special articles

\title{
ANONYMOUS
}

\section{Partners in Care}

\section{Psychiatric advance directives: a user's view}

I heard of advance directives being used in psychiatry at a MIND study day. The example was very much a directive, prohibiting the use of antidepressant drugs and electroconvulsive therapy (ECT). I have sufficient trust in my psychiatrist to feel that he should make such decisions on my behalf if required. I therefore felt a directive unnecessary.

Recently, however, I was admitted, deeply depressed, to a different ward than usual. Alone in my room, I refused to come out. I was therefore not given my drugs. As a result, I became very agitated in the night. It could have been avoided had my drugs been given. Transferred to my usual ward, my named nurse said 'We know you will stay in your room and need everything brought to you, but will start to come out as you feel better'. I made no request for relatives to be informed. When my sister visited, she was shocked to discover that I had been in hospital for 5 days before anyone was aware of my admission.

Once well, I reflected on these events, then produced a paper in consultation with my professional carers, not entitled 'advance directive' but 'notes on care'. It contains basic information about me, and relevant telephone numbers. I give details of relatives who should be informed of my admission even if I am saying I do not want anyone to know. I give instructions for my own safety, for instance my car keys must be taken from me, remembering I sometimes carry a spare set in my handbag. When this is done I get angry and frustrated, but when well I am convinced my instructions were correct. I also warn that if I have been feeling suicidal I might have an accumulation of drugs in my car. I describe my self-isolating behaviour.

I make no prohibitions regarding treatment, though I do mention ECT. I have had ECT but find the treatment unpleasant, even frightening. I state that if it is considered when I am not able to make my own decision, my psychiatrist and my sister should decide. I trust my consultant to take into account my antipathy.

My community psychiatric nurse, named nurse and consultant have copies of the directive. I include the request that a copy be given to the staff on any other ward to which I am admitted. I have had a very positive reaction from my professional carers. My named nurse wishes that other patients would do likewise. It leaves me confident that, in the event of my becoming ill again, matters will be dealt with in the manner I would have wished when well and able to make considered and reflective judgements about my care.

\section{Declaration of interest}

None. 